\title{
AN OLFACTORY INPUT TO THE HIPPOCAMPUS OF THE CAT: FIELD POTENTIAL ANALYSIS
}

\author{
A. M. M. C. HABETS*, F. H. LOPES DA SILVA** and W. J. MOLLEVANGER \\ Institute of Medical Physics TNO, Da Costakade 45, 3521 VS Utrecht (The Netherlands)
}

(Accepted June 7th, 1979)

Key words: hippocampus - field potential analysis - central olfactory connections

\section{SUMMARY}

Hippocampal responses to electrical stimulation of the prepyriform cortex in the cat were studied both in acute experiments under halothane anesthesia and in awake cats with chronically indwelling electrodes. Analysis of field potentials and unit activity indicated the extent to which different hippocampal subareas were activated, the laminar level at which the synaptic action took place and the dynamics of the evoked responses. It was found that: (1) the main generator of evoked responses in the hippocampus upon prepyriform cortex stimulation is localized in the fascia dentata and CA3 (CA1 pyramidal cells, and probably also subiculum cells, are activated but in a lesser degree); (2) the initial synaptic activity takes place at the most distal part of the dendrites of fascia dentata granule cells and CA3 pyramidal cells; and (3) this synaptic activity corresponds to an EPSP that leads to a transient increase in the firing rate of the hippocampal units, which is often followed by a long-lasting decrease in firing rate.

We conclude that the pathway from the prepyriform cortex via lateral entorhinal cortex to hippocampal neurons may enable olfactory inputs to effectively excite hippocampal neurons.

\section{INTRODUCTION}

Despite the large amount of data on hippocampal anatomy and physiology27, knowledge about information processing in the hippocampus is still fragmentary. At the beginning of this century the hippocampus was considered to be a part of the rhinencephalon, on the basis of its macroscopic anatomy, which implied a close association

* Present address: Netherlands Institute for Brain Research, IJdijk 28, 1095 KJ Amsterdam, The Netherlands.

** To whom reprint requests should be sent. 
of the hippocampus with the sense of smell. This idea has become less generally accepted since 1947, when Brodal ${ }^{8}$ stressed that even anosmatic mammals possess a well developed hippocampus. In fact, the olfactory input to the hippocampus is not even mentioned in some modern textbooks ${ }^{7}$. However, a projection from the prepyriform (olfactory) cortex (area 51) to the entorhinal cortex (area 28) in the rat has been described ${ }^{4,12,24}$. In the cat ${ }^{12}$, this projection appears to be less clear, but we have been able to confirm its existence ${ }^{18}$. Van Hoesen and Pandya ${ }^{21,22}$ showed that in the rhesus monkey the prepyriform cortex projects directly onto the entorhinal area. From the entorhinal cortex these inputs have access to the hippocampus proper by way of the perforant path $^{18,23,37}$.

Hippocampal responses to electrical stimulation of olfactory areas have a relatively short latency: $\mathrm{Cragg}^{11}$ found a field potential response in the hippocampus to electrical stimulation of the olfactory bulb in 5 mammalian species; in the cat, this response had a latency of 17 to $25 \mathrm{msec}$. Electrical stimulation in other sensory areas evoked less clear responses. The olfactory input to the hippocampus of the rat was confirmed by Woolley and Barron ${ }^{43}$. Way ${ }^{41}$ reported a similar response in the hippocampus of the cat after stimulation in olfactory areas, but no response after stimulation in visual areas. Yokota et al. ${ }^{44}$, using intracellular measurements, demonstrated a response in CA1 and CA3 hippocampal pyramidal cells on olfactory bulb stimulation in the awake squirrel monkey. This response was an EPSP with a latency of $15-17.5 \mathrm{msec}$ and lasting for 50-150 msec, but no spike generation was encountered.

From these data, it can be concluded that the hippocampus of the cat receives a relatively direct olfactory input. However, our knowledge is still very limited as regards both the spatial distribution of such an input to different sub-areas and laminae of the hippocampus, and its functional characteristics. To clarify these aspects was the main objective of the present study.

\section{MATERIALS AND METHODS}

The experiments were performed in 24 cats under halothane anesthesia and in 4 unanesthetized cats with chronically indwelling electrodes. In the acute experiments the EEG, rectal temperature and end-tidal $\mathrm{pCO}_{2}$ were continuously monitored. In these experiments the main recording area, the dorsal hippocampus, was exposed by aspirating the overlying cortex down to the lateral ventricle. The surface of the dorsal hippocampus was then covered with warm paraffin oil. Subsequently a number of stimulating/ recording electrodes were inserted in the following brain areas: olfactory bulb, prepyriform cortex, entorhinal area and hippocampus. A bundle of 4 stainless steel wires (diameter each wire $100 \mu \mathrm{m}$ ) with tip exposed over $0.3 \mathrm{~mm}$ and tip separation of $1.0 \mathrm{~mm}$ was placed stereotaxically into the olfactory bulb usually after opening the frontal sinus. While stimulating via the olfactory bulb electrodes (pulses of $200 \mu \mathrm{sec}$ duration and 500 $\mu \mathrm{A}, 1 / \mathrm{sec}$ ), an array of 4 stainless steel electrode bundles was lowered into the prepyriform cortex. Each bundle had 4 tips (diameter, $100 \mu \mathrm{m}$ ) exposed over $0.2 \mathrm{~mm}$ with a tip separation of $0.5 \mathrm{~mm}$; the inter-bundle distance was $2 \mathrm{~mm}$. These prepyriform cortex electrodes were fixed in place when the field potential characteristic of the superficial 
pyramidal layer was encountered (see Results). The reference electrode was either an $\mathrm{Ag}-\mathrm{AgCl}$ wire placed in a neck muscle or a stainless steel pin inserted into the contralateral occipital skull.

Recordings from the exposed hippocampus were made by means of an array of 4 electrodes, either glass micropipettes (filled with $3 \mathrm{M} \mathrm{KCl}$, tips $<5 \mu \mathrm{ml}$ ), or etched stainless steel wires (tips about $30 \mu \mathrm{m}$ ), which were inserted under visual control and according to known stereotaxic coordinates ${ }^{35}$. The 4 electrodes of the array were fixed in such a way that their tips were located along a line, with a variable tip separation dependent upon the objective of the experiment. The hippocampal electrode array was lowered by means of a microdriver (David Kopf instruments) or an electrically driven microstep driver. Within one penetration, recordings were made at distances varying from 250 to $10 \mu \mathrm{m}$. In a few experiments, hippocampal surface recordings were made by using a matrix of $3 \times 4$ stainless steel electrodes (diameter $100 \mu \mathrm{m}$ ). The matrix was constructed using a perspex plate with the electrode tips at $1.5 \mathrm{~mm}$ distance from each other and protruding $300 \mu \mathrm{m}$ under the plate. The electrode positions were histologically verified; for this purpose the brains were perfused with a solution of saline followed by $25 \%$ formalin to which potassium ferrocyanide was added. The Prussian blue reaction was used in order to localize the stainless steel electrodes.

In the chronic experiments, the same type of metal electrodes as described above were implanted in the olfactory bulb and the prepyriform cortex. Bundles of stainless steel wires (diameter $100 \mu \mathrm{m}$, tips: cut short, tip separation $0.5 \mathrm{~mm}$ ) were implanted bilaterally in the hippocampus; the ends of the wires were fixed to a plug cemented to the skull. In addition, several stainless steel pins were implanted in the frontal, occipital and/or temporal bone. These were used both as anchor points and for recording.

Stimulation. This was by means of current pulses delivered by a Digitimer-Neurolog system. Multichannel recording included a first stage of impedance transformation (FET circuits) followed by amplification (Tektronix FM 122) and filtering; the recorded signals were continuously monitored in a CRO (Tektronix RM 561 A); the evoked potentials were averaged on-line using an averager (CAT Mnemotron) and plotted (Hewlett Packard X-Y plotter). For off-line analysis the signals were stored on analog tape (Philips Analog 7).

Statistical analysis. The signals were digitized at a conversion rate of $2000 / \mathrm{sec}$ and stored on a cartridge disk of a PDP 11/20 computer. The mean, and standard deviation, S.D., of each time sample of the evoked potentials ( 96 additions) including a prestimulation period (10 msec duration) were computed. The latency of the evoked response was measured by finding the first sample that deviated from the prestimulus period by at least 2 S.D.

Spatial potential distribution. By using appropriate programs, the profiles of the amplitudes of averaged evoked potentials recorded at a certain time sample after the stimulus along one electrode track were computed.

Current source density analysis (CSD). As a measure for the trans-membrane current, a one dimensional current-source density was calculated at certain time samples from evoked potentials obtained in electrode tracks that run parallel to the hippocampal neurons. To this end, the second derivative of the field potential $(V)$ was computed using the formula: 


$$
\mathrm{CSD}=-\mathrm{g}_{\mathrm{x}} \cdot \frac{\mathrm{V}(\mathrm{x}+\mathrm{n} \Delta \mathrm{x})-2 \mathrm{~V}(\mathrm{x})+\mathrm{V}(\mathrm{x}-\mathrm{n} \cdot \Delta \mathrm{x})}{(\mathrm{n} \Delta \mathrm{x})^{2}}
$$

where $\mathrm{x}$ is the distance along the track, $\Delta \mathrm{x}==50 \mu \mathrm{m}$ and $\mathrm{g}_{\mathrm{x}}$ is the specific conductance in the $x$ direction (assumed to be constant). This analysis will be dealt with more extensively elsewhere ${ }^{19}$.

Analysis of unit firing. Unit (multiple or single cell) firing was first extracted from the field potentials by high pass filtering (between $300 \mathrm{~Hz}$ and $4 \mathrm{kHz}$ ). The unit spikes were then extracted by means of an amplitude discriminator as shown in Fig. 7. Analysis was performed either on-line using a special purpose computer of Average Transients (Mnemotron) or off-line by means of a PDP 11/20. Poststimulus time histograms were computed. The significance of changes in spike frequency was tested by means of a nonparametric test (Mann-Whitney).

Nomenclature. In the hippocampal complex, the following sub-areas are distinguished: area entorhinalis pars lateralis and pars medialis, the parasubiculum, presubiculum and subiculum. In the hippocampus proper, we distinguish (1) the fascia dentata, (2) the CA3 area, that receives the mossy fibres of the fascia dentata and coincides with the regio inferior of $\mathrm{Blackstad}^{6}$, and (3) the CAl area, that receives the Schaffer collaterals of $\mathrm{CA} 3$ and coincides with the regio superior of Blackstad. The determination of areas and their relative positions show some variation between species. We should therefore mention here a characteristic aspect of the cat's hippocampus. Between the CA1 and CA3 area in the cat a 'Misch-zone' 30 can be discriminated, characterized by the tapering of the bundle of mossy fibres towards CA1. This can be defined accurately by means of Timm's sulphide silver method ${ }^{20}$.

\section{RESULTS}

The choice of stimulation sites within the prepyriform cortex

To obtain an optimal localization of the stimulation electrodes in the prepyriform cortex, the olfactory bulb was electrically stimulated so that typical prepyriform cortex field potentials were elicited. The recording electrodes were lowered step by step into the structure until a polarity reversal of the evoked potentials was obtained indicating the position of the layer of the pyramidal cell somata (layer II, Price ${ }^{31}$ ), as illustrated in Fig. 1, and as has also been done by Woolley and Barron ${ }^{43}$. It was found that the shortest latency hippocampal-evoked potential was evoked by stimulation of the layer of the deep pyramidal cells. Stimulation of the molecular layer resulted in a retardation of the hippocampus evoked potential by about $4 \mathrm{msec}$. Therefore the electrodes straddling the prepyriform cortex layer II were selected as stimulating electrodes for further study of hippocampal evoked responses.

\section{Evoked potentials of entorhinal area and hippocampus}

In Fig. 2 typical evoked potentials in the hippocampus complex on prepyriform cortex stimulation are shown. Early and late components can be distinguished in these evoked potentials. The early component is a monophasic positive potential with a 


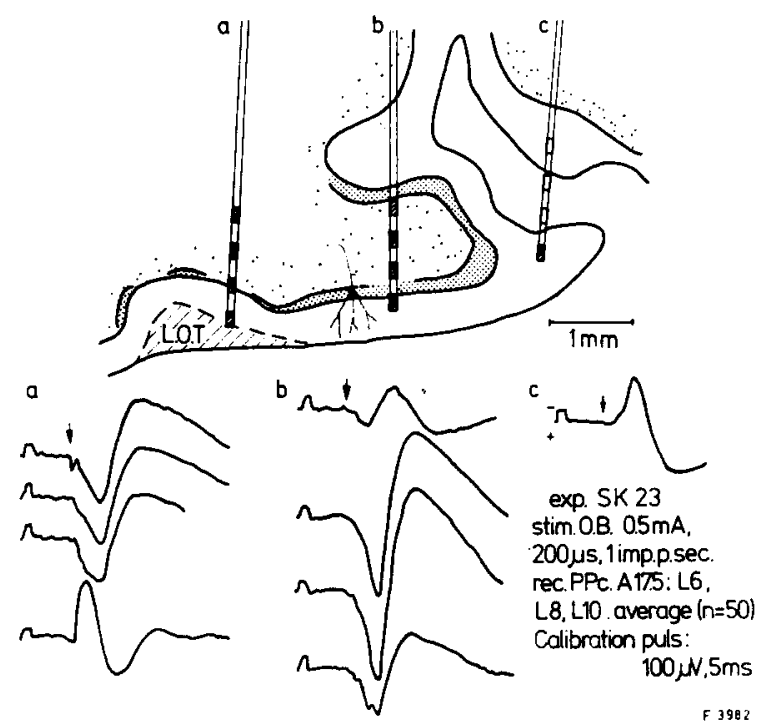

Fig. 1. Recording sites within the prepyriform cortex with the corresponding field potentials evoked by stimulation of the bulbus olfactorius. The moment of the stimulus is indicated by the arrow in this and following figures. Abbreviations: O.B., bulbus olfactorius; LOT, lateral olfactory tract.

duration of about 3-25 msec and a peak latency of 7-10 msec, which is clearly seen in the ventral hippocampus recordings (Fig. 2A) but is much less prominent in the dorsal hippocampus (Fig. 2B). In track a2, this early component presents a small positive deflection followed by a large negative deflection in the deepest cell layer of the lateral entorhinal area; the negative peak latency is $22 \mathrm{msec}$. The early component of track a1, and of the first 3 traces of a2, appears to be a volume-conducted field potential locally generated in the prepyriform cortex, on the basis of the very short latency $(<3$ $\mathrm{msec}$ ) and on the fact that this potential did not present a polarity reversal within the hippocampal complex. The last 3 traces of a 2 appear to result from the summation of this early component with another one, probably generated by the entorhinal area cells situated in the lateral part; these cells would receive monosynaptic prepyriform cortex inputs ${ }^{18}$. The generator of this component can be localized in the most ventral cell layers, (layer II and III), considering the location of the polarity reversal of this component. The late component, with onset at $22 \mathrm{msec}$ in the dorsal hippocampus, is a biphasic, initially positive potential in the fascia dentata, the polarity of which reverses near the hippocampus fissure in both the dorsal hippocampus (Fig. 2, b1) and the ventral hippocampus (Fig. 2, a1). This polarity reversal is located at the concave side of the hippocampal fissure at the level of the distal dendrites of the fascia dentata granule cells (Fig. 2C). It is absent in the CA3 track (Fig. 2B $\mathrm{B}_{\mathrm{b} 2}$ ). This polarity reversal of the evoked potential was encountered in all experiments where the hippocampal fissure was crossed in a perpendicular direction. In several experiments where penetrations were done in minute steps $(<50 \mu \mathrm{m})$, another less prominent polarity reversal over the pyramidal cell layer above the fascia dentata was encountered as described below.

In a number of experiments the distribution of field potentials over a dorsal hippo- 

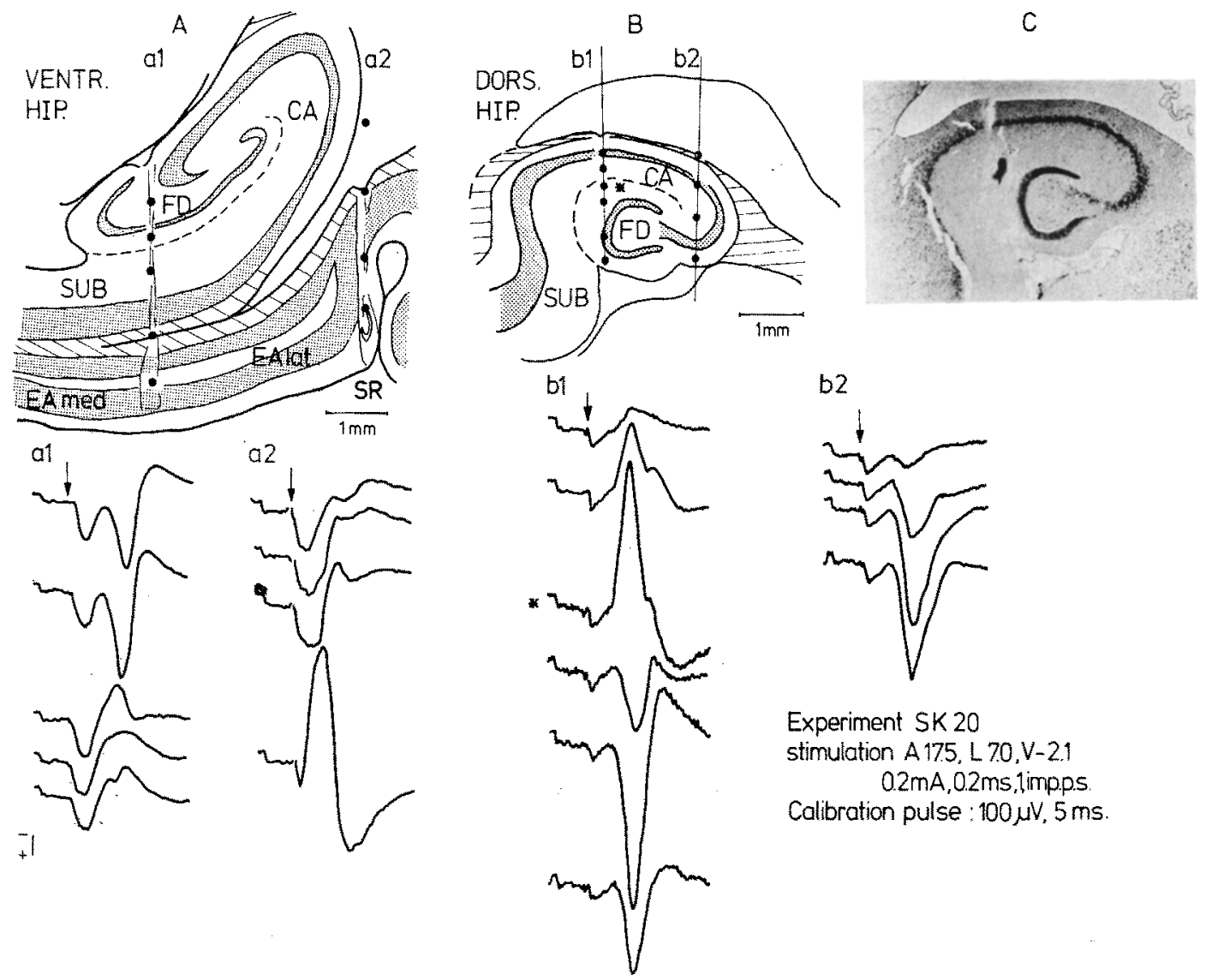

b2

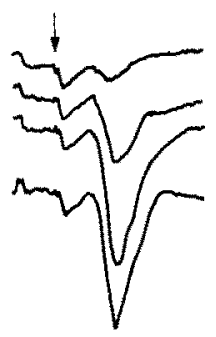

Experiment SK 20

stimulation $A 175, L 70, V-21$

$0.2 \mathrm{~mA}, 0.2 \mathrm{~ms}$, timpp.

Calibration pulse : $100 \mu \mathrm{V}, 5 \mathrm{~ms}$.

Fig. 2. Recording positions in the ventral hippocampus and adjacent entorhinal area with the corresponding evoked potentials on stimulation in the prepyriform cortex. For voltage and time calibration see calibration pulse and inset. B: As in A for the dorsal hippocampus. C: Prussian blue marking at the recording point indicated by an asterisk in $B$, traject bl. Further explanation in text. Abbreviations: CA, cornu ammonis; EAmed, medial entorhinal area; EAlat, lateral entorhinal area; FD, fascia dentata; SUB, subiculum.

campal section was determined using several microelectrodes placed parallel along the plane of a lamella. In this way a global analysis of the field potentials in different subareas was obtained. It could generally be observed that potential reversals occurred only in the molecular layers of CA3 and fascia dentata. Thus, at $40 \mathrm{msec}$ after the stimulus, the largest positivity was encountered in the hilus of the fascia dentata, which turned into negativity at the molecular layer. Negativity was recorded also over subiculum and CA1, but reversal to positivity was encountered at the molecular layer of CA3 above the hippocampal fissure.

The hippocampal responses could (with proper positioning of the stimulating electrodes) be evoked with current pulses as small as $0.2 \mathrm{~mA}$ and duration of $200 \mu \mathrm{sec}$, at a stimulus frequency of $1 / \mathrm{sec}$. Varying the stimulus amplitude from 0 to $3 \mathrm{~mA}$ caused the evoked potential amplitude to change, following a sigmoid curve, suggesting 


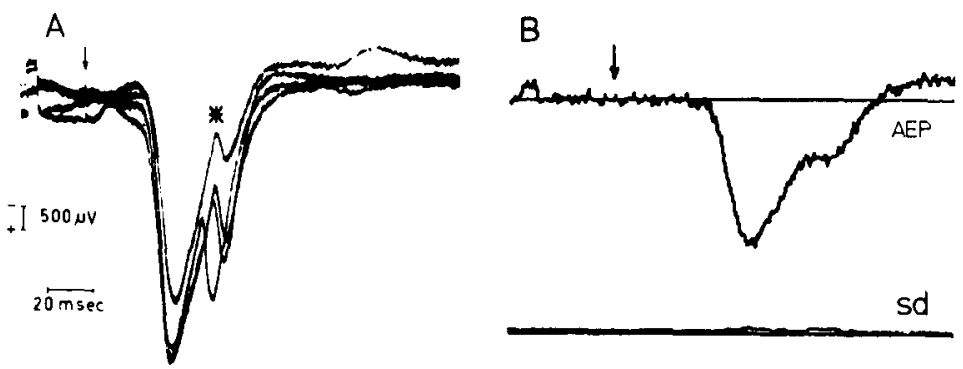

Fig. 3. A : recording from the fascia dentata granule cell layer (SK 23). Four CRO tracings of individual evoked potentials on stimulation in the prepyriform cortex are shown illustrating the occurrence of population spikes. This is the sharp negative going peak $\left(^{*}\right)$ at about $50 \mathrm{msec}$ after the stimulus. B: computer averaged evoked potential (AEP) under the same conditions $(n=96)$. Its standard deviation (S.D.) at the foot of the figure shows two little peaks that reflect the variability in the amplitudes of the positive evoked potential peak and the population spike. Calibration pulse: $500 \mu \mathrm{V}, 5 \mathrm{msec}$, upward deflection negative.

threshold and saturation phenomena. Increasing the stimulation frequency above 2 impulses/sec resulted in a marked decrease in the response amplitude and increase in the peak latency. No frequency-potentiation was noted in these experiments.

A population spike was noted in the individual evoked potential of several experiments. The population spike is a short duration negative going potential, caused by the nearly synchronously firing of a cell population ${ }^{1}$. Fig. 3 shows evoked potentials with a population spike recorded in the fascia dentata. A slight increase can be seen in S.D. of the corresponding average at the time of the population spike.

Laminar distribution of hippocampal potentials evoked on prepyriform cortex stimulation

It was of interest to be able to define the distribution of the hippocampal field potentials, evoked upon prepyriform cortex stimulation, according to the different hippocampal laminae. In order to do this, detailed recordings of evoked potentials were made along vertical tracks through the pyramidal cell layer into the fascia dentata granule cell layer (Fig. 4). In Fig. 4A two tracks are illustrated by means of potential profiles at 40, 55 and $70 \mathrm{msec}$ after stimulation in the prepyriform cortex (solid lines). Firstly, we shall consider the early part of the field potential, which shows a negative peak at about $40 \mathrm{msec}$ after the stimulus. At this time a polarity reversal from positive to negative is observed in the CA3 stratum radiatum. At greater depth the polarity reversal from negative to positive is reached in the molecular layer of the fascia dentata. Here, the penetrations were stopped in order to mark this reversal point by means of the Prussian blue reaction. Deeper in the fascia dentata the potential remains positive, as can be seen already in Fig. $4 \mathrm{~A}_{1}$; the positivity reaches large amplitudes at and below the soma layer, as illustrated in Figs. 2 and 3.

The polarity reversal in the fascia dentata (measured at $40 \mathrm{msec}$ after the stimulus) was found consistently. Considering the molecular layer as being subdivided into 4 parts, the polarity reversal was encountered in the second one, counting from the granular layer. Furthermore, two distinct maxima of negativity were found: one at the 

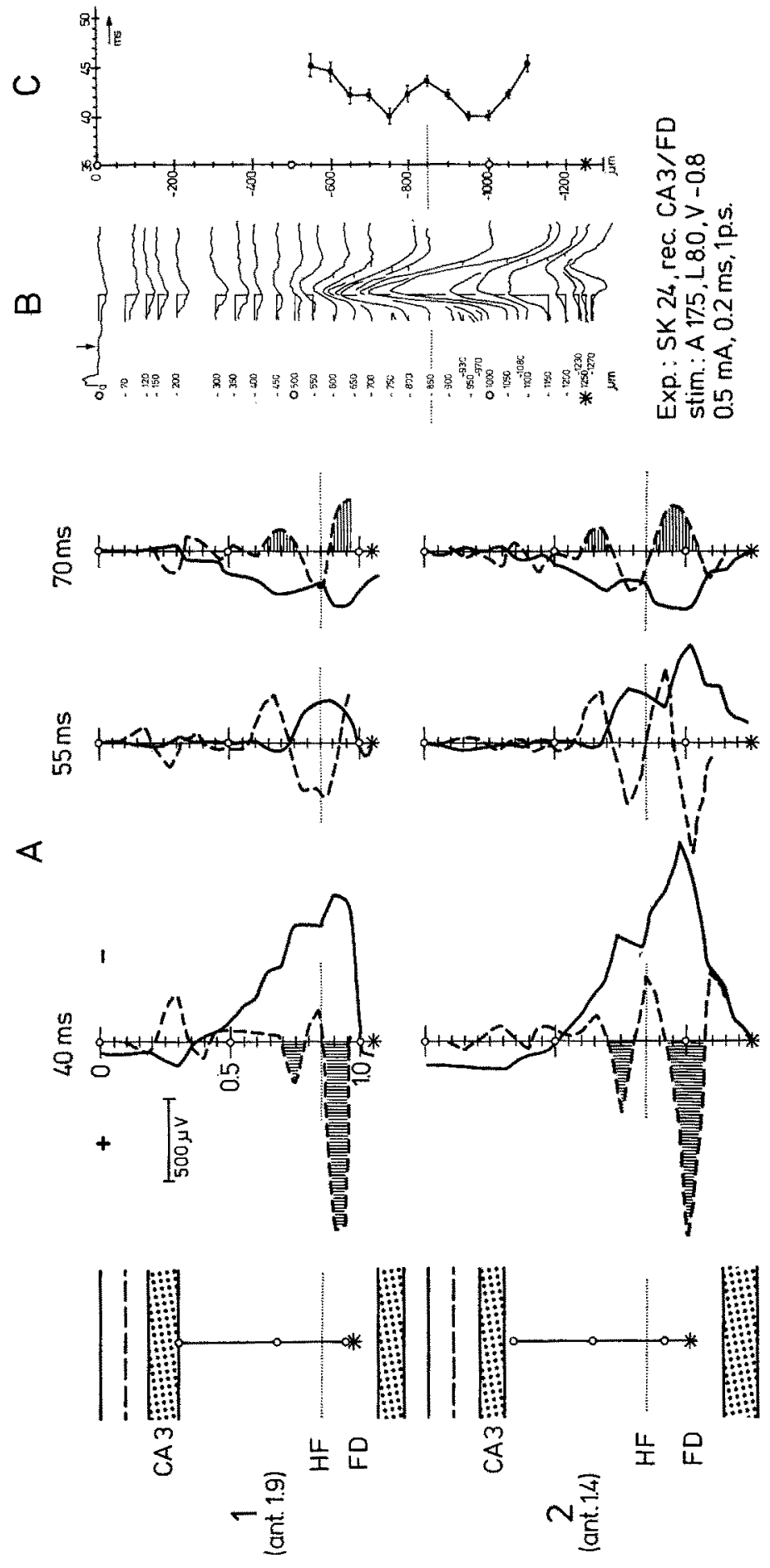
apical dendrites of the CA3 pyramidal cells, and the other at the distal part of the granule cell dendrites. These two maxima also correspond to the locations where the evoked potentials had the shortest peak latencies (Fig. 4C). However, it must be remarked here that, except for the marked reversal point, it was not possible to determine the anatomical location of the recording points with an accuracy exceeding $50 \mu \mathrm{m}$.

The evoked potentials were further studied by means of a current source density (CSD) analysis, as a more precise indication of the localization of the synaptic activity (Fig. 4A, broken line). At $40 \mathrm{msec}$ after the stimulus two separate current sinks were noted, flanked by sources. One sink was located at the distal end of the CA3 pyramidal cell dendrites, and the other at the distal end of the fascia dentata granule cell dendrites. This means that at these sites an inward-directed, positive ionic current was flowing into the hippocampal neurons.

Secondly, we consider the late part of the field potential. In Fig. 4A it can be seen at $70 \mathrm{msec}$ that the potential at the level around the fissure has become positive. This indicates that the initial excitatory synaptic action is followed by a secondary, presumably inhibitory, synaptic action. Assuming an excitatory synaptic action at the distal dendrites of a neuron, one can expect an active current sink with extracellular negativity at the distal dendrites, and a passive current source with extracellular positivity at the level of the soma. The opposite would be expected assuming an inhibitory synaptic action at the level of the distal dendrites. However, it should be stressed that in several experimental cases such a simplified account of field potentials may not be applicable directly. These considerations are treated from a biophysical point of view in a separate study ${ }^{19,33}$. The distal location of the amplitude maxima and latency minima of the early part of the evoked potential, experimentally observed, led us to conclude that the lateral perforant path is mainly involved here. This implies that the prepyriform cortex activates the hippocampus mainly along a pathway with a relay in the lateral entorhinal area.

In two experiments, the evoked potential distribution over the dorsal hippocampus was recorded by means of a matrix of 12 surface electrodes. With this matrix in two positions, the evoked potentials at 24 points over the dorsal hippocampal surface were measured on stimulation at 4 locations in the prepyriform cortex at different anterior

Fig. 4. A: two tracks through the pyramidal cell layer into the fascia dentata are shown with the corresponding potential profiles (solid line) and the current source densities (broken line) at different moments in time after stimulation in the prepyriform cortex. Each penetration was stopped and marked at the place where a polarity reversal negative to positive was encountered. This point is indicated by the asterisk. Note at $\mathbf{4 0} \mathrm{msec}$ the location of the two separate negative peaks in the potential profile, coincident with the current sinks (vertical shaded) and at $70 \mathrm{msec}$ the location of possible current sources (horizontal shaded). Amplitude calibration and polarity signs refer to potential profiles. As for the current source density profiles the positive sign designates inward directed ionic current into the cells (sink), while the negative sign designates outward directed ionic current (source). B: averaged evoked potentials from track A2; the vertical lines indicate $40 \mathrm{msec}$ after stimulation. Calibration pulse: 200 $\mu \mathrm{V}, 5 \mathrm{msec}$, upward deflection negative. C: latency (mean \pm S.E.) profile of the negative peak of the evoked potentials shown in (B). Note that the depths where the shortest peak latencies were encountered coincide with those where the current sinks were located (A2, $40 \mathrm{msec}$ ). 

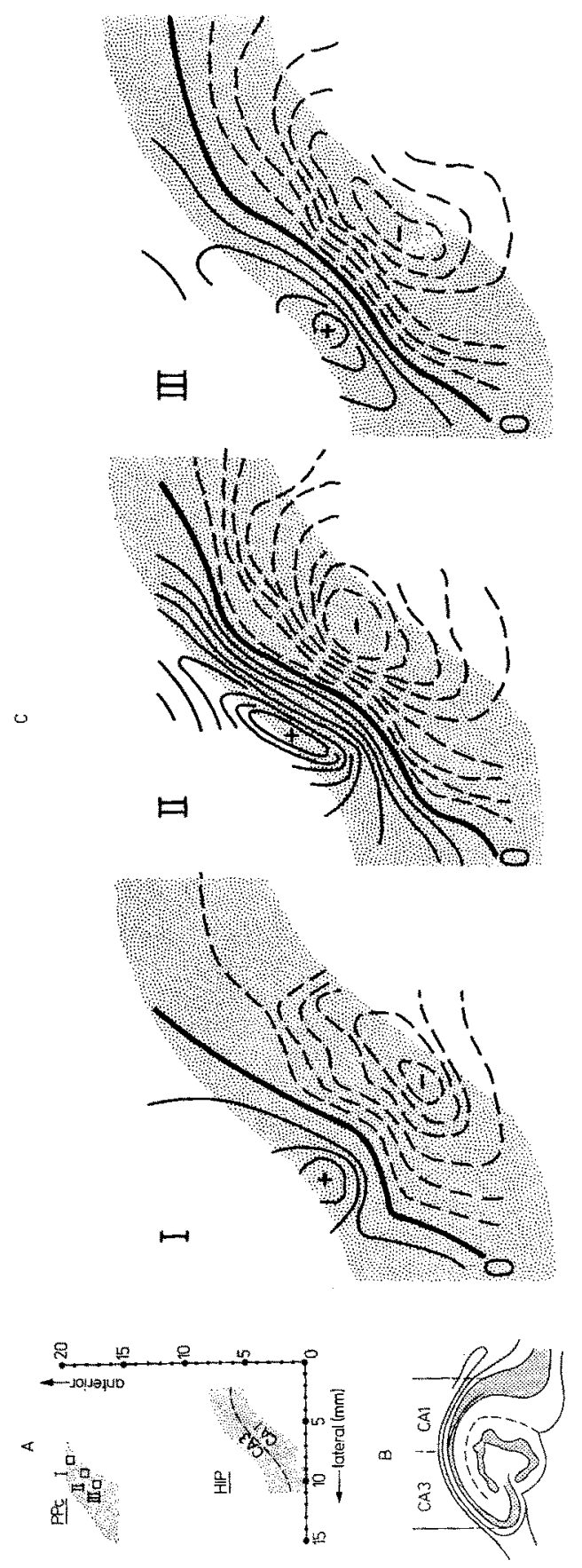

Fig. 5. A : projection of the prepyriform cortex (PPc) and the dorsal hippocampus (HIP) on a horizontal plane, illustrating the relative positions of 3 stimulation sites (I, II and III) and the hippocampus recording area. B: frontal section through the dorsal hippocampus (schematically) with indication of the borderlines of CA3 and CA1 as they are drawn in (A). C: evoked potential field on the dorsal hippocampal surface at $40 \mathrm{msec}$ after stimulation in the prepyriform cortex at the 3 indicated positions (I, II or III). Stimulation strength $1.5 \times$ threshold. Equipotential lines in arbitrary units. Note the position of the zero-equipotential line roughly above the CA3-CA1 border (which in fact is not a discrete border but corresponds to a gradual transition). 

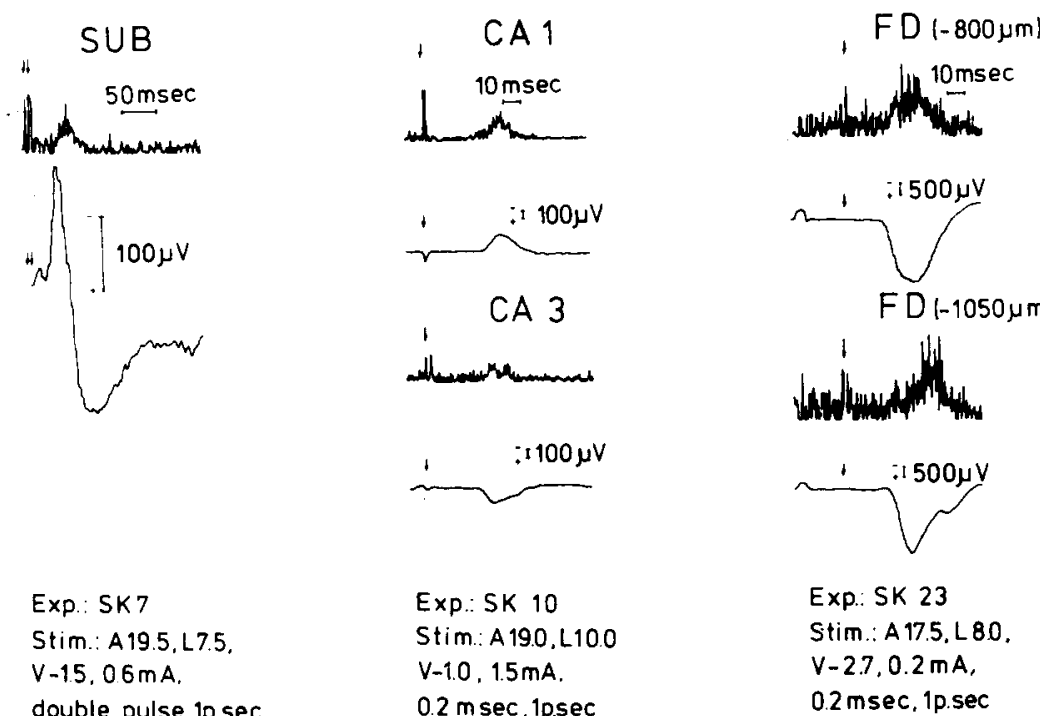

\author{
Exp: SK 7 \\ Stim.: A 19.5, L7.5, \\ $V-15,06 \mathrm{~mA}$. \\ double pulse ip.sec
}

Exp:: SK 10

Stim.: A 19.0.L10.0

$\mathrm{V}-1.0,1.5 \mathrm{~mA}$,

$0.2 \mathrm{~m} \mathrm{sec} .1 \mathrm{psec}$

Fig. 6. Relations between evoked potentials and poststimulus time histograms (PSTHs) of simultaneously recorded spike activity in subiculum (SUB), CA1, CA3 and fascia dentata (FD). Note two peaks in the PSTHs of the unit activity recorded in $\mathrm{CA} 3$ and the fascia dentata. Number of additions was 100 in each case.

positions (A 20.0-A 16.0) but at the same level of the prepyriform cortex pyramidal cell layer. At the different anterodorsal levels on the surface of the hippocampus, the polarity of the evoked potential appeared to be negative above the subiculum and CA1 and positive above $\mathrm{CA} 3$ and the fimbria, the polarity reversal situated roughly above the 'Mischzone' (Fig. 5). Stimulation at different sites in anterodorsal direction in the prepyriform cortex caused only minor changes in the position of the poles of the hippocampal surface field potentials. However, a simple topographic relationship between the prepyriform cortex stimulation sites and the position of the hippocampal poles could not be concluded. The positive and negative pole always appeared on a line approximately perpendicular to the longitudinal axis of the hippocampus; it presumably indicates the direction of the parallel-oriented hippocampal circuitry (lamellae).

\title{
Hippocampal potentials evoked on stimulation of other basal forebrain areas
}

Stimulation in the olfactory bulb resulted in a hippocampal-evoked potential that occurred 12-15 msec later, and had a duration of about 1.5-2 times longer than the evoked potential upon prepyriform cortex stimulation. However, the wave form and topography of the olfactory bulb- and prepyriform cortex-evoked field potentials were essentially the same. Stimulation medial to the lateral olfactory tract, namely in the tuberculum olfactorium, and either medial or dorsal to this area resulted in evoked potentials that could vary both in wave form and onset latencies (these ranged from 10 to $54 \mathrm{msec}$ ) from the potentials evoked upon prepyriform cortex stimulation. The short latency responses were presumably caused by activation of the Diagonal Band of Broca near the medial wall of the frontal olfactory cortex, and subsequent hippocampal 

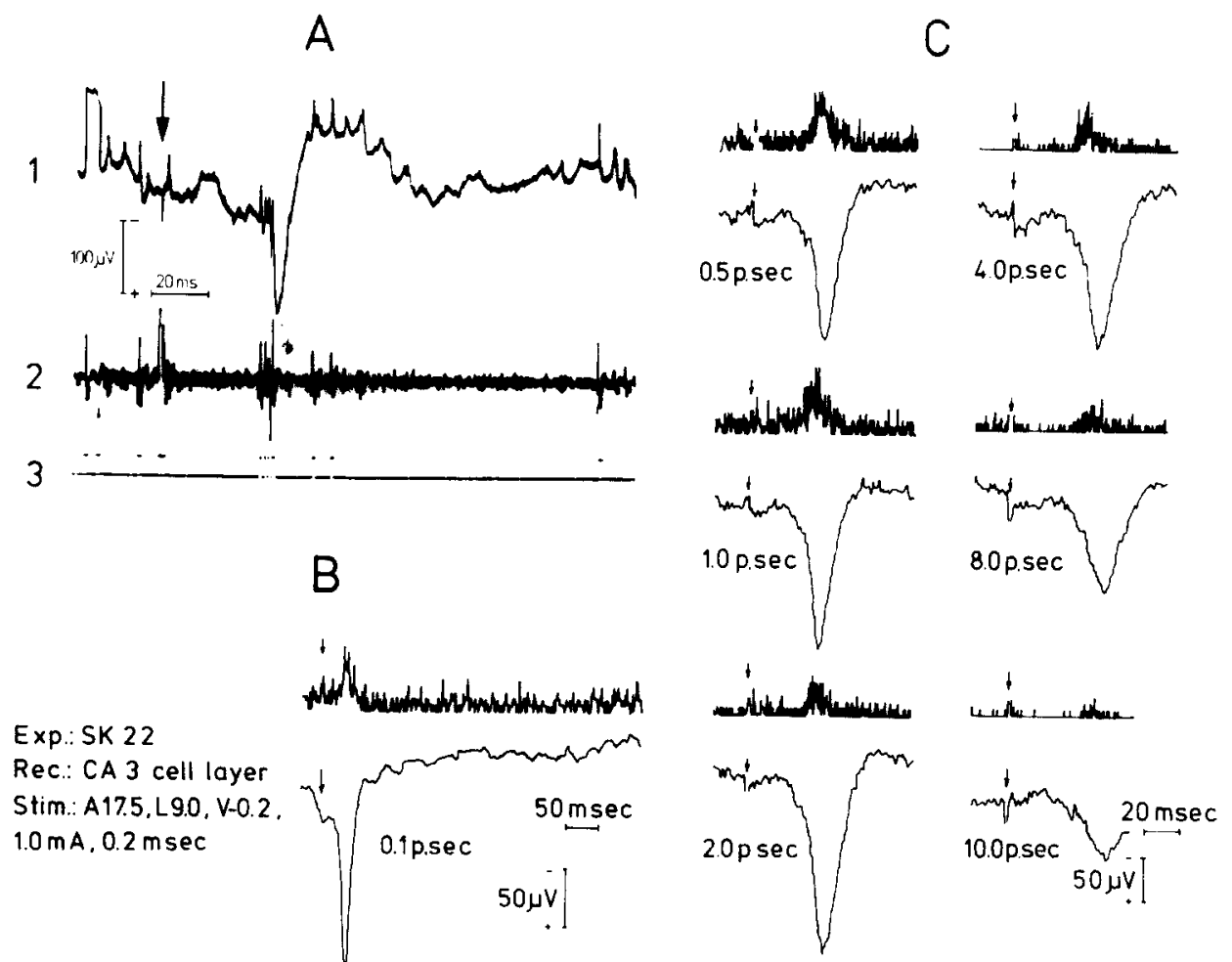

Exp.: SK 22

Rec.: CA 3 cell layer

Stim: A17.5, L9.0, V-0.2. $1.0 \mathrm{~mA}, 0.2 \mathrm{msec}$
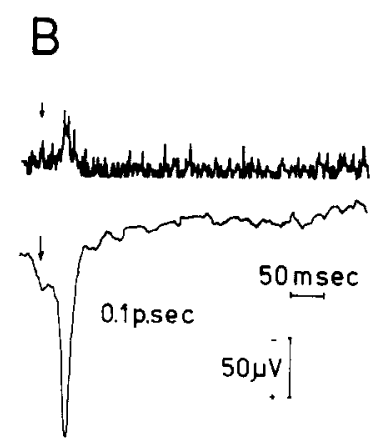

Fig. 7. A : field potential and (multi-)unit activity in CA3 soma layer evoked by a single pulse (indicated by arrow) applied to the prepyriform cortex (stimulation rate $0.1 \mathrm{p} / \mathrm{sec}$ ). Al, low pass signal (0.8-1250 $\mathrm{Hz}$ ). Note burst of 4 spikes at the beginning of the (positive) evoked response, suggestive of a population spike; A2, high pass signal ( $300-4000 \mathrm{~Hz}$ ); A3, amplitude discriminator output. The unit pulses were counted to generate the PSTH shown in (B). At the beginning of trace Al a calibration pulse $(100 \mu \mathrm{V}$, $5 \mathrm{msec}$ ) is shown which also appears in the unit pulse traces, as well as the stimulus artefact. B and C: relations between evoked potentials and PSTHs of the simultaneously recorded unit activity in the CA3 pyramidal cell layer on increasing stimulation rates in the prepyriform cortex. Note the long-lasting decrease in the firing rate on stimulation at $0.1 \mathrm{p} / \mathrm{sec}(\mathrm{B})$. Note also the decreasing reak amplitude of the initial increase in firing rate with increasing stimulus frequency and the concomitant decrease in amplitude and increase in latency of the positive peak in the evoked potentials (C). Number of additions was 30 in (B) and 100 in (C).

activation along the septo-hippocampal pathway. These evoked responses were not further investigated.

\section{Hippocampal evoked potentials in chronic cats}

The evoked potentials reported above were all measured in acute experiments under halothane anesthesia. In chronic preparations (awake cats), the hippocampal evoked potentials upon prepyriform cortex stimulation had the same waveforms, as far as the component representing the primary synaptic action is concerned (i.e. from 20 to $50 \mathrm{msec}$ after stimulation). It should be noted that the hippocampus was not scanned as systematically and precisely in the chronic as in the acute experiments. A great degree of similarity between evoked potentials recorded in acute and chronic pre- 

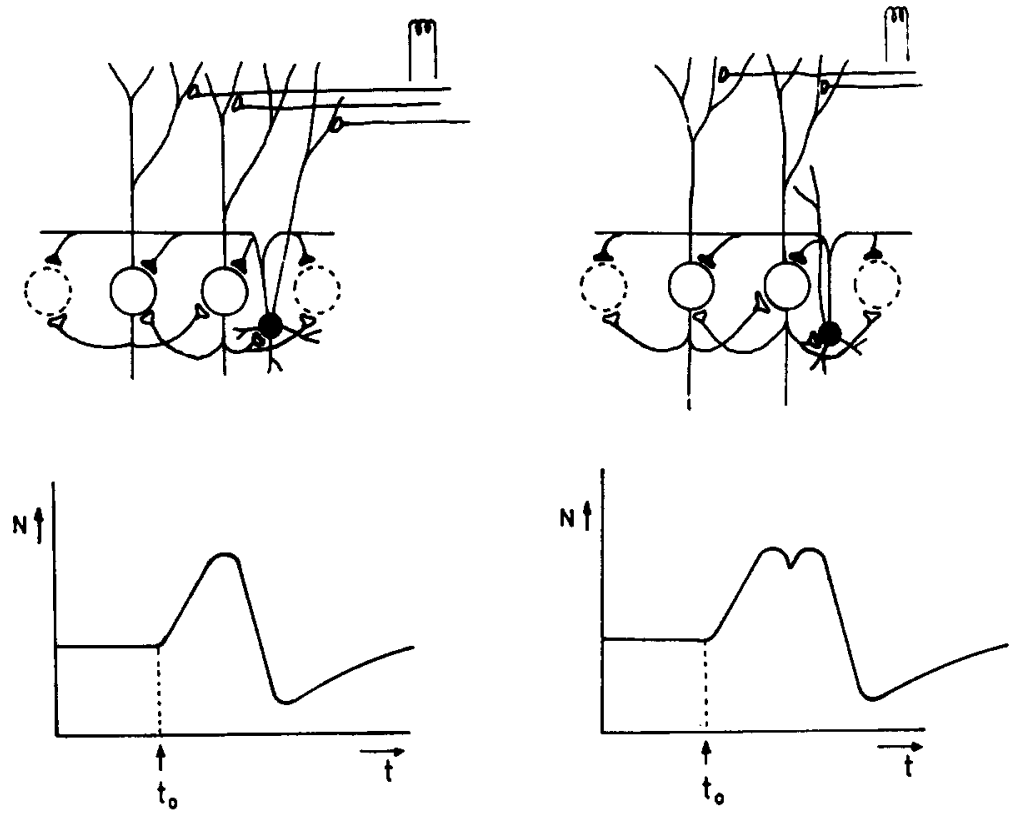

Fig. 8. Diagram presenting possible neuronal circuits with the expected PSTHs. Left: case of a feedforward inhibition via a basketcell (black) and mutual excitation of the projection neurons. Right: case of recurrent inhibition by way of a basketcell (black) and mutual excitation of the projection neurons. The right model could explain the decrease in firing rate of hippocampal units that is observed experimentally after an initial increase causing a double-peaked PSTH.

parations, in which approximately the same stimulation and recording sites were used, was encountered. In these experiments, however, and also in one chronic animal that was brought under anesthesia for this purpose ${ }^{39}$, some distinctions could be made: firstly, in the chronic animals usually a higher threshold was noted for hippocampal potentials evoked upon prepyriform cortex stimulation. Secondly, the amplitude of the late negative component in the hippocampal-evoked potential (at the level of the fascia dentata granular layer) was higher in the chronic animals than in acute preparations.

\section{Hippocampal unit firing following prepyriform cortex stimulation}

In a number of acute experiments, evoked cell firing was encountered and analyzed (Figs. 6 and 7). Cells in subiculum, CA1 and CA3 and fascia dentata appeared to respond to prepyriform cortex stimulation with spike frequency increase with onset at 25-30 msec after the stimulus, often followed by a subsequent spike-frequency decrease. In a number of chronic animals these results were reproduced and further elaborated. This will be reported elsewhere ${ }^{39}$.

A clear relation appeared between the evoked potential and changes in unit firing, viz. there was an increase in firing rate during the initial part of the evoked response. However, the polarity of the evoked potential peaks was not a cue for the kind of changes in firing rate. This phenomenon has been discussed before in the literature ${ }^{16,25,32}$. In this study we encountered changes in unit activity in areas where the evoked potential 
polarity reversal indicates a local response, such as the fascia dentata and CA3. However, in the subiculum and CAl, where no polarity reversal was encountered, units which increased their firing rate on prepyriform cortex stimulation were also encountered. That was the case in 4 out of 16 units. Whether these units correspond to cells or fibres passing through the subiculum is not certain. It should be noted that at least some of these action potentials probably originate from fibres, considering that they were triphasic (positive-negative-positive) with a duration of $0.6-0.7 \mathrm{msec}$.

The effect of increasing the prepyriform stimulus frequency upon the evoked potential and upon simultaneously registered unit activity in the CA3 pyramidal cell layer is illustrated in Fig. 7. To a stimulus frequency of $1 / \mathrm{sec}$, it appears that the decrease in spike frequency which follows the initial increase in the poststimulus time histogram can last for over $500 \mathrm{msec}$. This probably accounts for the decrease in evoked potential amplitude at stimulation rates above $2 / \mathrm{sec}$ as reported above. These phenomena may be interpreted as being caused by recurrent inhibition well known to exist in the CAI, CA3 and fascia dentata 2 .

\section{DISCUSSION}

The prepyriform cortex response to electrical stimulation in the bulbus olfactorius as shown in this study in the cat agrees with earlier reports $5,15,43$. The evoked potential in the hippocampus to electrical stimulation in the prepyriform cortex is, in general terms, also similar to earlier reports ${ }^{11,41,43}$. The more detailed measurements and analysis of the present study, however, permit further conclusions to be made regarding the following aspects: ( 1 ; what is the relative participation of the different hippocampal sub-areas in the evoked potential; (2) within which lamina of the hippocampus does the synaptic action take place; (3) what kind of synaptic activity is mainly involved, and what are its dynamics.

Firstly, it can be concluded from the field potential analysis that the main generator of the evoked potential is situated in the fascia dentata and that the CA3 area contributes additionally to the initial components of the evoked potential. The CA1 area and subiculum do not seem to be involved directly, as judged from the field potential analysis. Secondly, it follows from the depth profile of the evoked potential through the CA 3 and fascia dentata areas that the initial synaptic activity triggered by prepyriform cortex stimulation is localized at the most distal part of the apical dendrites of CA3 pyramidal cells and the distal dendrites of the fascia dentata granule cells. This localization of the initial synaptic activity also emerges from the negative peak latency profile and from the current source density analysis. Additionally, secondary synaptic actions are concluded (vide infra). Thirdly, the polarity distribution of the evoked potential along the cells permits us to interpret this initial synaptic activity as an excitatory synaptic potential. Moreover, the excitatory nature of the initial synaptic activity emerges both from the recorded unit activity and the occurrence of population spikes on prepyriform cortex stimulation. Despite the distal site on the dendrites, the excitatory postsynaptic potential evoked upon stimulation in the prepyriform cortex, was powerful enough to change the firing rate of hippocampal neurons. This is particularly note- 
worthy in view of the work of Yokota et al.44, who found excitatory postsynaptic potentials but no changes in the firing rate of hippocampus pyramidal cells in the squirrel monkey upon olfactory bulb stimulation. On the other hand, this may be in keeping with the suggestions of Cragg ${ }^{11}$ that the olfactory input to the hippocampus becomes less important as the rung on the phylogenetic ladder becomes higher. The observed changes in firing rate on prepyriform cortex stimulation not only characterize the initial action on the hippocampus neurons as excitatory but suggest also secondary inhibitory synaptic activity. This inhibitory activity can last over $500 \mathrm{msec}$, as has also been reported by others ${ }^{2,14}$.

A possible mechanism for this inhibitory activity could be an excitation of inhibitory interneurons such as the basket cells, either by way of collaterals of axons of the initially excited pyramidal or granular cells, or by means of a feed-forward excitation via prepyriform cortex input directly on these interneurons, as suggested by Andersen ${ }^{2}$. The latter possibility can probably be discarded, however, if we take into account that in several poststimulus time histograms of units in subiculum, CA3 and fascia dentata, two crests within the initial spike frequency increase can be seen with an interval of 5-10 msec. This can be considered as an indication for mutual excitation ${ }^{16}$ between the pyramidal or the granule cells on the initial excitation triggered by the prepyriform cortex stimulus. In the case of feed-forward onto inhibitory interneurons, this second crest would probably not appear, as it would coincide with the feed-forward inhibition (Fig. 8).

In contrast with the primary excitatory synaptic activity distal on the cell dendrites, the secondary inhibitory synaptic activity is not clearly observed in the current source density analysis. This might be expected in view of the characteristics of the inhibitory activity: low amplitude and long duration. This matter will be discussed on theoretical grounds more extensively elsewhere ${ }^{19}$. It should be noted that, in the chronic preparation, the threshold of hippocampal evoked potentials was higher than in the acute experiments and that the amplitude of the late component ( $>50-60 \mathrm{msec}$ after the stimulus) was larger. These two findings suggest a higher level of inhibition in the awake state in this brain area than during halothane anesthesia.

The participation of the pyramidal cells of CA3 in the evoked potentials, together with the fascia dentata granule cells, is demonstrated both by field potential analysis and by the poststimulus time histograms of the unit activity elicited by prepyriform cortex stimulation. However, units in CA1 and the subiculum also participate, judging from the analysis of the unit recordings (see ref. 39). This could indicate that the perforant fibres that travel out of the angular bundle through the subicular layer make synaptic contacts 'en route' with subiculum and CA1 pyramidal cells, but the possibility that some unit activity recorded in this area is picked up from the perforant fibres themselves has been already indicated in the results section. Activation of only pyramidal cells was never observed upon prepyriform cortex stimulation in the present study, which is in contrast to the results reported by Gloor, Vera and Sperti ${ }^{17}$, who occasionally observed a response from the pyramidal cells only (and not from the fascia dentata) upon stimulation 'in the entorhinal cortex or the amygdala'. These contrasting results may be explained by taking into consideration the fact that different pathways were 
probably involved in the two studies: on the one hand (Gloor et al. ${ }^{17}$ ) from the basolateral part of the amygdala via layer III of the entorhinal area ${ }^{26}$, selectively to CAl and subiculum ${ }^{38}$; on the other hand (present study) from the prepyriform cortex via lateral entorhinal area layer $\mathrm{I}^{18}$. In the latter case, entorhinal cells in both layer II and III would also be innervated, and these neurons project to the fascia dentata and CA3 as well as to CAl and subiculum ${ }^{38}$.

Cragg ${ }^{11}$ and Woolley and Barron ${ }^{43}$ interpreted the response in the hippocampus, evoked upon prepyriform cortex stimulation, simply as a synaptic action on the apical dendrites of the pyramidal cells, thus not taking into account the participation of the granule cells. Recently, the olfactory input to the granule cells via the lateral entorhinal cortex has been demonstrated clearly in the rat ${ }^{42}$, similarly to what is reported here in the cat. No input to $\mathrm{CA} 3$ was reported in that study, however, nor was involvement of CAl detected by means of the applied laminar profile technique.

The present study was concerned with an olfactory projection to the hippocampus of the cat. Other sensory inputs are reported in the literature as well. It has been shown anatomically that neocortical areas which receive afferent outflow from auditory, visual and somatosensory systems converge onto the entorhinal area ${ }^{21,22}$. Thus, these other sensory modalities have a much less direct connection to the entorhinal area than does the olfactory system.

From literature reports on electrophysiological studies of other sensory inputs to the hippocampus, one gets the impression that only long latency hippocampal unit responses ( 50 to several hundred $\mathrm{msec}$ ) can be obtained in response to light and tone stimuli. This was found both in the rabbit ${ }^{36,40}$ and in the cat ${ }^{9}$. Extensive unit measurements of MacLean and co-workers ${ }^{10,13,28,29}$ in the squirrel monkey showed no visual input at all, either to the hippocampus or to the entorhinal cortex. On the other hand, these authors showed a clear visual response in units in the posterior hippocampal gyrus. Segal ${ }^{34}$ reported a response in CA3 neurons, with a latency of $96 \mathrm{msec}$, following conditioning to tone stimulation in rat. In contrast, an evoked potential of short latency (18-35 $\mathrm{msec})$ in CA1 and CA 3 after peripheral stimulation of the sciatic nerve in rabbits was reported by Artemenko ${ }^{3}$.

It is concluded from this study that olfactory inputs from the prepyriform cortex reach the hippocampal neurons, especially the fascia dentata granule cells along lateral entorhinal relays. This pathway appears to be initially excitatory.

\section{ACKNOWLEDGEMENTS}

We thank F. de Quartel and A. van Veen for their assistance with the histology and W. ten Broeke and J. G. Lommen for their assistance in the computer analysis of the experimental results. The encouragement and criticisms of W. Storm van Leeuwen, A. van Rotterdam and A. Tielen are also gratefully acknowledged. Finally, the authors thank M. A. Corner for polishing the English.

This work was partly supported by the Foundation for Medical Research (FUNGO) which is subsidized by the Netherlands Organization for the Advancement of Pure Research (ZWO). 


\section{REFERENCES}

1 Andersen, P., Bliss, T. V. P. and Skrede, K. K., Unit analysis of hippocampal population spikes, Exp. Brain Res., 13 (1971) 208-222.

2 Andersen, P., Gross, G. N., Lømo, T. and Sveen, O., Participation of inhibitory and excitatory interneurons in the control of hippocampal cortical output. In M. A. B. Brazier (Ed.), The Interneuron, University of California Press, Los Angeles, 1969, pp. 415-465.

3 Artemenko, D. P., Laminar analysis of hippocampal potentials evoked by peripheral stimulation, J. Neurophysiol., 2 (1970) 434-438.

4 Beckstead, R. M., Afferent connections of the entorhinal area in the rat as demonstrated by retrograde cell labelling with horseradish peroxidase, Brain Research, 152 (1978) 249-264.

5 Biedenbach, M. A. and Stevens, C. F., Electrical activity in cat olfactory cortex produced by synchronous orthodromic volleys, J. Neurophysiol., 32 (1969) 193-203.

6 Blackstad, T. W., Commissural connections of the hippocampal region in the rat, with special reference to their mode of termination, J. comp. Neurol., 105 (1956) 417-536.

7 Brazier, M. A. B., Electrical Activity of the Nervous System, Pitman Medical Publishing Company Ltd., Kent, 1977.

8 Brodal, A., The hippocampus and the sense of smell, Brain, 70 (1947) 179-222.

9 Brown, M. W. and Horn, G., Responsiveness of neurons in the hippocampal region of anaesthesized and unanaesthesized cats to stimulation of sensory pathways, Brain Research, 123 (1977) 241-259.

10 Casey, K. L., Cuenod, M. and MacLean, P. D., Unit analysis of visual input to posterior limbic cortex. II. Intracerebral stimuli, J. Neurophysiol., 28 (1965) 1118-1131.

11 Cragg, B. G., Responses of the hippocampus to stimulation of the olfactory bulb and of various afferent nerves in five mammals, Exp. Neurol., 2 (1960) 547-572.

12 Cragg, B. G., Olfactory and other afferent connections of the hippocampus in the rabbit, rat and cat, Exp. Neurol., 3 (1960) 588-600.

13 Cuenod, M., Casey, K. L. and MacLean, P. D., Unit analysis of visual input to posterior limbic cortex. Photic stimulation, J. Neurophysiol., 28 (1965) 1101-1117.

14 Finch, D. and Babb, Th. L., Response decrement in a hippocampal basket cell, Brain Research, 130 (1977) 354-359.

15 Freeman, W. J., Distribution in time and space of prepyriform electrical activity, J. Neurophysiol., 22 (1959) 644-666.

16 Freeman, W. J., Relations between unit activity and evoked potentials in prepyriform cortex of cats, J. Neurophysiol., 31 (1968) 337-348.

17 Gloor, P., Vera, C. L. and Sperti, L., Electrophysiological studies of hippocampal neurons. I. Configuration and laminar analysis of the 'resting' potential gradient, of the main-transient response to perforant path, fimbrial and mossy fibre volleys and of 'spontaneous activity', Electroenceph. clin. Neurophysiol., 15 (1963) 353-378.

18 Habets, A. M. M. C., Lopes da Silva, F. H. and De Quartel, F. W., Autoradiography of an olfactory hippocampal pathway in the cat with special reference to the perforant path, Exp. Brain Res., in press.

19 Habets, A. M. M. C., Van Rotterdam, A., Lopes da Silva, F. H., Synthesis of hippocampal field potentials evoked by prepyriform cortex stimulation in the cat: experiments and model, in preparation.

20 Haug, F. M., Heavy metals in the brain. A light microscope study of the rat with Timm's sulphide silver method. Methodological considerations and cytological and regional staining patterns, Advanc. Anat. Embryol. Cell Biol., 47 (1973) 1-71.

21 Van Hoesen, G. W. and Pandya, D. N., Some connections of the entorhinal (area 28) and perirhinal (area 35) cortices of the rhesus monkey. I. Temporal lobe afferents, Brain Research, 95 (1975) 1-24.

22 Van Hoesen, G. W., Pandya, D. N. and Butters, N., Some connections of the entorhinal (area 28) and perirhinal (area 35) cortices of the rhesus monkey. II. Frontal lobe afferents, Brain Research, 95 (1975) 25-38.

23 Van Hoesen, G. W. and Pandya, D. N., Some connections of the entorhinal (area 28) and perirhinal (area 35) cortices of the rhesus monkey. III. Efferent connections, Brain Research, 95 (1975) 39-59.

24 Hjorth-Simonsen, A., Projection of the lateral part of the entorhinal area to the hippocampus and fascia dentata, J. comp. Neurol., 146 (1972) 219-232.

25 John, E. R. and Morgades, P. P., The pattern and anatomical distribution of evoked potentials and multiple unit activity elicited by conditioned stimuli in trained cats, Commun. Behav. Biol., 3 (1969) 181-207. 
26 Krettek, J. E. and Price, J. L., Projections of the amygdala to the perirhinal and entorhinal cortices and the subiculum, Brain Research, 71 (1974) 105-154.

27 Lopes da Silva, F. H. and Arnolds, D. E. A. T., Physiology of the hippocampus and related structures, Ann. Rev. Physiol., 40 (1978) 163-191.

28 MacLean, P. and Creswell, G., Anatomical connections of visual system with limbic cortex of monkey, J. comp. Neurol., 138 (1970) 265-278.

29 MacLean, P. D., Yokota, T. and Kinnard, M., Photically sustained on responses of units in posterior hippocampal gyrus of awake monkey, J. Neurophysiol., 31 (1968) 870-873.

30 McLardy, T., Some cell and fibre peculiarities of uncal hippocampus. In W. Bargmann and J. P. Schadé (Eds.), The Rhinencephalon and Related Structures, Progress in Brain Research, Vol. 3, 1963, pp. $71-88$.

31 Price, J. L., An autoradiographic study of complementary laminar patterns of termination of afferent fibres to the olfactory cortex, J. comp. Neurol., 150 (1973) 87-108.

32 Ramos, A., Schwartz, E. and John, E. R., Evoked potential-unit relationships in behaving cats, Brain Res. Bull., 1 (1976) 69-75.

33 Van Rotterdam, A., A one-dimensional formalism for the computation of extracellular potentials: linear systems analysis applied to volume conduction, in preparation.

34 Segal, M., Flow of conditioned responses in limbic telencephalic system of the rat, $J$. Neurophysiol., 36 (1973) 840-854.

35 Snider, R. S. and Niemer, W. T., A Stereotaxic Atlas of the Cat Brain, The University of Chicago Press, Chicago, 1964.

36 Stafekhina, V.S. and Vinogradova, O. S., Sensory characteristics of the cortical input to the hippocampus: the entorhinal cortex, $Z H$ Vyssa Nerv. Deiat., 25 (1975) 410-420.

37 Steward, O., Topographic organization of the projections from the entorhinal area to the hippocampal formation of the rat, J. comp. Neurol., 167 (1976) 285-314.

38 Steward, O. and Scoville, S. A., Cells of origin of entorhinal afferents to the hippocampus and fascia dentata of the rat, J. comp. Neurol., 169 (1976) 347-370.

39 Tielen, A. M., Habets, A. M. M. C., Lopes da Silva, F. H. and Mollevanger, W. J., Hippocampal unit activity during olfactory pathway stimulation in cats, in preparation.

40 Vinogradova, O. S., Sanyonova, T. P. and Konovalov, V. Ph., Trace phenomena in single neurons of hippocampus and mammillary bodies. In H. Pribram (Ed.), Biology of Memory, Academic Press, New York, 1970, pp. 191-221.

41 Way, J. S., An oscillographic study of afferent connections to the hippocampus in the cat (Felis domesticus), Electroenceph. clin. Neurophysiol., 14 (1962) 78-89.

42 Wilson, R. C. and Steward, O., Polysynaptic activation of the dentate gyrus of the hippocampal formation: an olfactory input via the lateral entorhinal cortex, Exp. Brain Res., 33 (1978) 523-534.

43 Woolley, D. E. and Barron, B. A., Hippocampal responses evoked by stimulation of the prepyriform cortex in the rat, Electroenceph. clin. Neurophysiol., 24 (1968) 63-74.

44 Yokota, T., Reeves, A. G. and MacLean, P. D., Differential effects of septal and olfactory volleys on intracellular responses of hippocampal neurons in awake sitting monkeys, $J$. Neurophysiol., 33 (1970) 96-107. 